\title{
Individual and Area Level Socioeconomic Status and Its Association with Cognitive Function and Cognitive Impairment (Low MMSE) among Community-Dwelling Elderly in Singapore
}

\author{
Liang En Wee ${ }^{a}$ Wei Xin Yeo ${ }^{a}$ Gui Rong Yang ${ }^{a}$ Nazirul Hannan ${ }^{a}$ \\ Kenny Lim ${ }^{a}$ Christopher Chua ${ }^{a}$ Mae Yue Tan ${ }^{a}$ Nikki Fong ${ }^{a}$ \\ Amelia Yeap $^{\mathrm{a}}$ Lionel Chen $^{\mathrm{a}}$ Gerald Choon-Huat Koh $^{\mathrm{b}}$ Han Ming Shen ${ }^{\mathrm{b}}$ \\ aYong Loo Lin School of Medicine and ${ }^{b}$ Saw Swee Hock School of Public Health, National University of \\ Singapore, National University Health System, Singapore, Singapore
}

\section{Key Words}

Cognitive impairment $\cdot$ Socioeconomic status $\cdot$ Neighborhood $\cdot$ Asia

\begin{abstract}
Background/Aims: Neighborhood socioeconomic status (SES) can affect cognitive function. We assessed cognitive function and cognitive impairment among community-dwelling elderly in a multi-ethnic urban low-SES Asian neighborhood and compared them with a higher-SES neighborhood. Methods: The study population involved all residents aged $\geq 60$ years in two housing estates comprising owner-occupied housing (higher SES) and rental flats (low SES) in Singapore in 2012. Cognitive impairment was defined as $<24$ on the Mini Mental State Examination. Demographic/clinical details were collected via questionnaire. Multilevel linear regression was used to evaluate factors associated with cognitive function, while multilevel logistic regression determined predictors of cognitive impairment. Results: Participation was 61.4\% (558/909). Cognitive impairment was found in $26.2 \%$ (104/397) of residents in the low-SES community and in $16.1 \%(26 / 161)$ of residents in the higher-SES community. After adjusting for other sociodemographic variables, living in a low-SES community was independently associated with poorer cognitive function $(\beta=-1.41, S D=0.58, p<0.01)$ and cognitive impairment (adjusted odds ratio $5.13,95 \% \mathrm{Cl} 1.98-13.34)$. Among cognitively impaired elderly in the low-SES community, $96.2 \%$ $(100 / 104)$ were newly detected. Conclusion: Living in a low-SES community is independently associated with cognitive impairment in an urban Asian society.

Copyright $\odot 2012$ S. Karger AG, Basel
\end{abstract}




\section{Introduction}

The link between individual socioeconomic status (SES) and cognitive impairment is well established in the literature [1-3]. However, research on area level SES and health has increased in recent decades. A significant body of work focuses on mental health and deprived neighborhoods, with several recent Western studies linking neighborhood SES and cognitive impairment. Wight et al. [5] first documented an association between neighborhood educational attainment and cognitive function; subsequent studies have further validated the link between cognitive impairment and living in a deprived neighborhood, independent of individual SES [6-12]. The elderly are particularly vulnerable to neighborhood SES as their social space shrinks due to decreased mobility, limiting their interactions to their immediate community [13]. Several theories have been posited to link neighborhood SES and mental health, such as the 'collective resources' and 'local social inequality' models posited by Stafford and Marmot [14]. In the 'collective resources' model, people living in areas with better social and material collective resources enjoy better health, whereas in the 'local social inequality' model, disparities between individuals' socioeconomic position and the socioeconomic conditions of their local area may interact to influence health $[14,15]$. In cognitive impairment, deprived neighborhoods may have less resources and opportunities for social engagement [10] and interactions protective against cognitive decline [16, 17] as residents keep mostly to themselves, given weaker community identity.

However, less is known about SES and cognitive impairment in Asian societies. In Asian societies, individual socioeconomic characteristics are linked with cognitive impairment [18-21]. Multiple individual socioeconomic risk factors interact synergistically to affect cognitive impairment [21] and cognitive impairment is higher in lower-educated suburban neighborhoods [22]. However, no previous Asian studies on cognitive impairment have looked at the interplay between area level and individual SES. Given widening income inequality in Asian societies [23], investigating this interplay may help achieve more equitable access to health services for those with cognitive impairment in Asian societies. Singapore is one such multi-ethnic urbanized Asian society, with Chinese, Malay, and Indian populations. The prevalence of cognitive impairment among community-dwelling elderly was estimated at $30 \%$ in a 2007 study $[24,25]$. Singapore is the fastest ageing country in the AsiaPacific after Japan [26], with dementia as a major cause of disability [27]. Locally, cognitive impairment has been linked to ethnicity and educational level [25, 28]; however, the impact of area level SES has not been studied. Singapore has one of the highest rates of income inequality in Asia, with a Gini coefficient of 0.452 in 2011 [29] (the Gini coefficient being a measure of income inequality, with 0 reflecting complete income equality and 1 reflecting maximum income inequality). Locally, equitable access to healthcare is a major issue. Home ownership is a key local indicator of SES. The majority of Singaporeans $(\geq 85 \%)$ live in owner-occupied public housing; home ownership is high (90.1\%) due to government subsidies [30]. Public rental flats provide heavily subsidized rentals (26-275 SGD/month) [31] for the needy ( $<3 \%$ of the population), especially the needy elderly [32], with $88 \%$ of those living in rental housing earning $<670 \mathrm{SGD} /$ month [33]. In line with the government's policy of promoting social integration, these blocks of public rental flats are not concentrated in certain areas but are built within the same locations as owner-occupied public housing. Thus, given close geographical proximity of communities of differing area level SES in land-scarce Singapore, we could study cognitive impairment and SES in selected contrasting neighborhoods [4]. As such, we investigated the relationship between individual and area measures of SES and cognitive impairment within a community-dwelling population of elderly aged $\geq 60$ years, living in two integrated Singaporean housing precincts containing both lower area SES (public rental housing) and higher area SES (owner-occupied public housing) communities. 
ee et al.: Individual and Area Level Socioeconomic Status and Its Association with

Cognitive Function and Cognitive Impairment among Community-Dwelling Elderly

\section{Methods}

\section{Study Population}

The study population involved all Singaporean residents aged $\geq 60$ years living in two integrated public housing sites in Singapore. Rental flats are distributed across four geographical zones; we chose one site in the western zone and another site in the eastern zone as these two zones had the highest concentrations of public rental flats [34]. Site A contains 6 blocks, 3 of which predominantly consist of heavily subsidized public rental flats and the remaining 3 blocks, immediately adjacent, predominantly consist of owner-occupied public flats. Site B contains 9 blocks, 7 of which are predominantly public rental flats and 2, immediately adjacent, are predominantly owner-occupied public flats. These two sites comprised all the public rental flats in their respective estates, as well as all the owner-occupied blocks that were immediately adjacent to them. Prior to study commencement, we surveyed these 15 blocks to determine how many residents were aged $\geq 60$ years. A total of 385 residents in Site A (191 from rental flats, 194 from owner-occupied housing) and 524 residents in Site B (434 from rental flats, 90 from owner-occupied housing) were eligible.

\section{Study Methodology}

Over a 1-month period from January to February 2012, residents $\geq 60$ years of age were visited door-to-door to (1) collect baseline information, such as sociodemographic data/ medical history, via interviewer-administered standardized questionnaires and (2) assess for cognitive impairment using the Mini Mental State Examination (MMSE), which has been translated into Chinese and Malay and validated in the local population [25, 28]. At baseline, we collected sociodemographic data, assessed functional status using the Lawton-Brody Instrumental Activities of Daily Living (iADL) scale [35] and the Shah-modified Barthel Index [36]; measured medical comorbidity burden using the Charlson Comorbidity Index [37]; social support using the Lubben Social Network Scale-6 (LSNS-6) [38, 39], and depressive symptoms using the Geriatric Depression Scale (GDS-15) where a score of $\geq 5$ is suggestive of depression [40]. Body mass index (BMI) and blood pressure were also measured. The questionnaire was administered by teams of trained 4th year medical students who had completed psychiatry rotations, under the supervision of a physician. To ensure standardization, all teams underwent compulsory training sessions prior to study commencement, with refresher courses at regular intervals. To minimize linguistic barriers, the questionnaire was translated into Chinese, Malay, and Tamil and administered by interviewers conversant in those languages. Based on MMSE scores, residents were offered various services. Residents with MMSE scores below the locally validated cutoffs for cognitive impairment were referred to public primary care clinics called polyclinics for follow-up, while cognitively normal residents were offered a free community-based mental wellness program (Nurture Your Mind) by the national Health Promotion Board [41]. Ethics approval was obtained from the National University of Singapore Institutional Review Board. Informed consent was sought from participants or their caregivers (if the participant was incapable of giving informed consent) and participation was voluntary.

\section{Definitions}

\section{Cognitive Impairment}

Cognitive impairment was defined as an MMSE score $<24$, a cutoff that has been previously validated locally in both Chinese and Malay populations with good sensitivity and specificity [25]. We did not stratify cutoffs by educational level, despite lower educational levels in our study population, but instead introduced education as a covariate into the multivariate analysis $[28,42,43]$. 
Dement Geriatr Cogn Disord Extra 2012;2:529-542

DOI: $10.1159 / 000345036$

Published online: November 20, 2012

2012 S. Karger AG, Base

www.karger.com/dee

Wee et al.: Individual and Area Level Socioeconomic Status and Its Association with

Cognitive Function and Cognitive Impairment among Community-Dwelling Elderly

\section{Individual and Area Level SES}

Individual level measures of SES included individual employment status, vehicle ownership status, monthly household income, and being a recipient of financial aid. Area level measures of SES included whether the resident was living in a block predominantly composed of public rental units. Rental blocks as an area level indicator of SES has also been shown to influence chronic disease management independently of individual level SES in previous local studies $[44,45]$. In our study, we analyzed differences in area level SES at the block level; each block had about 165 households. Additionally, for each block, we also calculated indices of neighborhood deprivation, using factor analysis and the following six measures of neighborhood SES: (1) percentage of families that are composed of husband and wife; (2) percentage of households dependent on public assistance; (3) percentage of households which have an annual income above the median; (4) percentage of adults without secondary education; (5) percentage of housing units that are rentals, and (6) adult unemployment rate. These measures are commonly used in the existing literature on area level SES $[10,46,47]$ and could be computed in our local setting. As block level census data was unavailable from the national Department of Statistics, the relevant block level percentages were calculated using information collected as part of a previous study [48] that surveyed all adult residents aged $\geq 40$ years living in the same two integrated public housing sites, for which the participation rate was $78.2 \%$. This dataset was assembled over 2009-2011 and the data was collected independent of, and prior to, the current study, thus ensuring proper temporal sequencing. We then used these six measures to calculate an index of neighborhood deprivation via factor analysis [49]. A principal components factor analysis revealed that the six measures segregated into two empirical factors based on an eigenvalue of 1 and the scree plot (eigenvalues 3.34 and 1.06, explained variance 55.59 and $17.72 \%$, respectively). The first factor contained high loadings on the percentage of those married (-0.76), on financial aid (0.74), rentals (0.93), household income more than the median (-0.75), and adults with lower education (0.77). We termed this factor 'neighborhood disadvantage'. The second factor contained high loadings on the percentage of those unemployed (0.79). We termed this factor 'neighborhood unemployment'. The loadings for each factor were used to compute a neighborhood disadvantage and a neighborhood unemployment factor score for each subject (after reverse scoring the variables with negative weights). Because the number of areas $(n=15)$ was small, we did not analyze the scores/indices of neighborhood deprivation as a continuous variable but instead stratified into 'disadvantaged' versus 'not disadvantaged' (neighborhood disadvantage score), and 'unemployed' versus 'not unemployed' (neighborhood unemployment score).

\section{Statistical Analysis}

Descriptive statistics were computed for the study population. We used $\chi^{2}$ analysis to examine sociodemographic and clinical differences between the low area SES community and the high area SES community (i.e. rental versus owner-occupied). Hierarchical linear models were then used to estimate the variance in cognition (measured by the MMSE score). The variance in cognition associated with the neighborhood context at the block level was first estimated with a null model containing only a random intercept. Subsequently, the impact of individual level demographic, clinical, and socioeconomic factors was tested. Finally, the main effect of area level SES on cognition was assessed. We then examined the independent associations of individual and area level SES with cognitive impairment (MMSE score <24) using multi-level logistic regression, controlling for within-group correlation by residential blocks. The criterion for initial entry of variables into multivariate models was $\mathrm{p}<0.2$ on univariate analysis; collinear variables $(|\mathrm{r}|>0.6)$ were omitted from the final models in order of decreasing $\mathrm{p}$ values. Statistical analysis was performed using SPSS (version 17.0, USA), STATA (version 11.0, USA) and HLM (version 6.01, USA), and statistical significance was set at $\mathrm{p}<0.05$. 
Wee et al.: Individual and Area Level Socioeconomic Status and Its Association with

Cognitive Function and Cognitive Impairment among Community-Dwelling Elderly

\section{Results}

The overall response rate was 61.4\% (558/909). The response rate in Site A was $61.0 \%$ $(235 / 385)$ and in Site B it was 61.6\% (323/524). There was no difference in response between sites. However, overall the response rate was higher from the rental (lower area SES) blocks compared to the owner-occupied (higher area SES) blocks (63.7\%, 397/625, vs. $56.7 \%$, $161 / 284, p=0.0473$ ). A more detailed profile of participants can be found in table 1 . Generally, as expected, the elderly residing in rental flats were less well-off compared to their counterparts dwelling in owner-occupied blocks, having lower household income and lower educational attainment with increased need for financial aid; and this trend held true across both study sites. Elderly in owner-occupied flats also had better social support compared with their counterparts dwelling in rental blocks. For the dependent variable (MMSE), the mean MMSE was 25.64 (SD = 4.23). The range of scores was from 12 to 30; although the sample was in general cognitively well-functioning, some individuals had marked deficits. Only $2.7 \%(15 / 558)$ received a perfect score, alleviating concerns about a ceiling effect.

\section{Overall Neighborhood Variation in Cognitive Function}

Our initial analysis using a null model revealed statistically significant between-neighborhood variation in cognitive functioning between blocks $(\tau=2.10, \mathrm{p}<0.001)$. The intraclass correlation $(\rho)$, however, was 0.119 , indicating that $11.9 \%$ of the variation in cognition in this sample could be attributed to living in different blocks (table 2).

\section{Model of Cognitive Function}

Prior to examining area level variables, cognitive functioning was regressed on the individual's demographic characteristics and socioeconomic factors (table 2). Model 2 added individual level demographic and clinical factors, which accounted for $19.2 \%$ of the individual level within-group variance. Largely consistent with previous research, increased age $[20,28]$, Chinese (majority) ethnicity, female gender [18-20], lower education [28], having a smaller social network, hearing impairment, and dependence in iADL [50] were all associated with poorer cognitive function. Model 3 added individual level socioeconomic factors, which accounted for another additional $4.5 \%$ of the individual level variance in cognition. As shown, being currently employed was positively and significantly associated with cognition. The coefficients for the other individual level demographic and clinical factors were largely unchanged by controlling for individual level SES. Model 4 added the main effects on cognitive functioning of the three area level variables (rental vs. non-rental, neighborhood deprivation, neighborhood unemployment). Model 3 is nested within model 4 , hence the difference in their deviation scores tests the null hypothesis that the coefficients for the additional variables all equal 0 , a hypothesis we rejected $\left(\chi^{2}=10.74\right.$, d.f. $=3, \mathrm{p}<0.05$ ). Living in a low-SES area (whether by rental versus non-rental, or by a higher neighborhood deprivation score) was associated with low cognitive function, independent of individual level SES and other covariates. The coefficients for the individual level variables were largely unchanged, with the exception of that of ethnicity, for which there was a noticeable decrease; this suggests that area level SES accounted for some of ethnicity's effect on cognition.

\section{Model of Cognitive Impairment}

In our study population of community-dwelling elderly, the prevalence of cognitive impairment (MMSE score $<24)$ was $23.3 \%(130 / 558)$. Of these, 8 had a prior history of doctordiagnosed dementia, with equal numbers in rental and owner-occupied blocks. Six of them 
Table 1. Sociodemographic characteristics of community-dwelling elderly $(n=558)$ living in rental blocks and owner-occupied blocks in two integrated public housing precincts in Singapore

\begin{tabular}{|c|c|c|c|c|c|c|c|c|c|}
\hline \multirow[t]{2}{*}{ Characteristic } & \multicolumn{2}{|c|}{ Precinct A $(\mathrm{n}=235)$} & \multirow[t]{2}{*}{$\mathrm{p}$ value $^{\mathrm{a}}$} & \multicolumn{2}{|c|}{ Precinct $B(n=323)$} & \multirow[t]{2}{*}{$\mathrm{p}$ value $^{\mathrm{a}}$} & \multicolumn{2}{|c|}{ Total $(\mathrm{n}=558)$} & \multirow[t]{2}{*}{ p value ${ }^{a}$} \\
\hline & $\begin{array}{l}\text { owner- } \\
\text { occupied } \\
(\mathrm{n}=107)\end{array}$ & $\begin{array}{l}\text { rental } \\
(\mathrm{n}=128)\end{array}$ & & $\begin{array}{l}\text { owner- } \\
\text { occupied } \\
(\mathrm{n}=54)\end{array}$ & $\begin{array}{l}\text { rental } \\
(\mathrm{n}=269)\end{array}$ & & $\begin{array}{l}\text { owner- } \\
\text { occupied } \\
(\mathrm{n}=161)\end{array}$ & $\begin{array}{l}\text { rental } \\
(\mathrm{n}=397)\end{array}$ & \\
\hline \multicolumn{10}{|l|}{ Demographics } \\
\hline \multicolumn{10}{|l|}{ Age } \\
\hline $60-70$ years & $59(55.1)$ & $56(43.8)$ & \multirow[t]{2}{*}{0.090} & $25(46.3)$ & $123(45.7)$ & \multirow[t]{2}{*}{1.000} & $84(52.2)$ & $179(45.1)$ & 0.135 \\
\hline$\geq 71$ years & $48(44.9)$ & $72(56.2)$ & & $29(53.7)$ & $146(54.3)$ & & $77(47.8)$ & $218(54.9)$ & \\
\hline Gender & & & & & & & & & \\
\hline Male & $40(37.4)$ & $51(39.8)$ & 0.788 & $21(38.9)$ & $138(51.3)$ & 0.103 & $61(37.9)$ & $189(47.6)$ & 0.039 \\
\hline Female & $67(62.6)$ & $77(60.2)$ & & $33(61.1)$ & $131(48.7)$ & & $100(62.1)$ & $208(52.4)$ & \\
\hline Marital status & & & & & & & & & \\
\hline Not currently married & $44(41.1)$ & $71(55.5)$ & 0.036 & $19(35.2)$ & $139(51.7)$ & & $63(39.1)$ & $210(52.9)$ & 0.004 \\
\hline Currently married & $63(58.9)$ & $57(44.5)$ & & $35(64.8)$ & $130(48.3)$ & 0.036 & $98(60.9)$ & $187(47.1)$ & \\
\hline Ethnicity & & & & & & & & & \\
\hline Malay & $26(24.3)$ & $45(35.2)$ & Referent & $7(13.0)$ & $64(23.8)$ & Referent & $33(20.5)$ & $109(27.5)$ & Referent \\
\hline Chinese & $67(62.6)$ & $64(50.0)$ & 0.270 & $37(68.5)$ & $183(68.0)$ & 0.155 & $104(64.6)$ & $247(62.2)$ & 0.175 \\
\hline Indian & $8(7.5)$ & $15(11.7)$ & 0.560 & $9(16.7)$ & $20(7.4)$ & 0.059 & $17(10.6)$ & $35(8.8)$ & 0.397 \\
\hline Other & $6(5.6)$ & $4(3.1)$ & 0.842 & $1(1.9)$ & $2(0.7)$ & 0.337 & $7(4.3)$ & $6(1.5)$ & 0.209 \\
\hline Highest educational attainment & & & & & & & & & \\
\hline No formal education & $34(31.8)$ & $66(51.6)$ & Referent & $9(16.7)$ & $97(36.1)$ & Referent & $43(26.7)$ & $163(41.1)$ & Referent \\
\hline Primary education & $50(46.7)$ & $41(32.0)$ & 0.006 & $18(33.3)$ & $113(42.0)$ & 0.324 & $68(42.2)$ & $154(38.8)$ & 0.054 \\
\hline Secondary or higher education & $23(21.5)$ & $21(16.4)$ & 0.052 & $27(50.0)$ & $59(21.9)$ & 0.007 & $50(31.1)$ & $80(20.2)$ & 0.019 \\
\hline Socioeconomic indicators & & & & & & & & & \\
\hline Currently employed & $33(30.8)$ & $29(22.7)$ & 0.182 & $9(16.7)$ & $80(29.7)$ & 0.065 & $42(26.1)$ & $109(27.5)$ & 0.833 \\
\hline Car ownership (yes) & $4(3.7)$ & $0(0.0)$ & 0.042 & $6(11.1)$ & $14(5.2)$ & 0.119 & $10(6.2)$ & $14(3.5)$ & 0.170 \\
\hline Monthly household income & & & & & & & & & \\
\hline$<500$ SGD & $19(19.0)$ & $58(46.0)$ & Referent & $11(20.4)$ & $107(40.4)$ & Referent & $30(19.5)$ & $165(42.2)$ & Referent \\
\hline$\geq 500,<1,000$ SGD & $30(30.0)$ & $37(29.4)$ & 0.023 & $15(27.8)$ & $83(31.3)$ & 0.265 & $45(29.2)$ & $120(30.7)$ & 0.012 \\
\hline$\geq 1,000$ SGD & $51(51.0)$ & $31(24.6)$ & $<0.001$ & $28(51.9)$ & $75(28.3)$ & 0.009 & $79(51.3)$ & $106(27.1)$ & $<0.001$ \\
\hline On financial aid & $18(16.8)$ & $30(23.4)$ & 0.256 & $1(1.9)$ & $49(18.2)$ & 0.001 & $19(11.8)$ & $79(19.9)$ & 0.027 \\
\hline Geriatric history & & & & & & & & & \\
\hline History of falls & & & & & & & & & \\
\hline$\geq 1$ fall in past year & $26(24.3)$ & $30(23.4)$ & 0.879 & $9(16.7)$ & $59(21.9)$ & 0.467 & $35(21.7)$ & $89(22.4)$ & 0.911 \\
\hline General health & & & & & & & & & \\
\hline Visual impairment & $8(7.5)$ & $21(16.4)$ & 0.046 & $6(11.1)$ & $42(15.6)$ & 0.530 & $14(8.7)$ & $63(15.9)$ & 0.030 \\
\hline Hearing impairment & $6(5.6)$ & $11(8.6)$ & 0.454 & $4(7.4)$ & $26(9.7)$ & 0.798 & $10(6.2)$ & $37(9.3)$ & 0.312 \\
\hline Systolic blood pressure ${ }^{\mathrm{b}}$ & $138.2 \pm 18.5$ & $137.9 \pm 16.7$ & 0.897 & $131.4 \pm 13.4$ & $139.6 \pm 20.4$ & $<0.001$ & $136.0 \pm 17.3)$ & $139.1 \pm 19.3$ & 0.066 \\
\hline Diastolic blood pressure ${ }^{\mathrm{b}}$ & $81.8 \pm 10.9$ & $81.6 \pm 12.4$ & 0.884 & $81.5 \pm 8.62$ & $80.6 \pm 12.8$ & 0.535 & $81.7 \pm 10.1)$ & $81.0 \pm 12.6$ & 0.454 \\
\hline Underweight (BMI <18.5) & $10(9.6)$ & $6(4.9)$ & 0.199 & $1(2.0)$ & $29(11.2)$ & 0.039 & $11(7.1)$ & $35(9.2)$ & 0.499 \\
\hline Overweight (BMI $\geq 23$ ) & $65(62.5)$ & $71(58.2)$ & 0.586 & $20(39.2)$ & $135(52.3)$ & 0.094 & $85(54.8)$ & $206(54.2)$ & 0.924 \\
\hline Depression $^{c}$ & $16(15.0)$ & $33(25.8)$ & 0.053 & $8(14.8)$ & $71(26.4)$ & 0.083 & $24(14.9)$ & $104(26.2)$ & 0.004 \\
\hline Functional history & & & & & & & & & \\
\hline iADL (Lawton-Brody iADL scale <8) & $19(17.8)$ & $27(21.1)$ & 0.621 & $3(5.6)$ & $37(13.8)$ & 0.114 & $22(13.7)$ & $64(16.1)$ & 0.519 \\
\hline Basic ADL (Barthel Index $<100$ ) & $13(12.1)$ & $21(16.4)$ & 0.457 & $3(5.6)$ & $51(94.4)$ & 0.591 & $16(9.9)$ & $44(11.1)$ & 0.764 \\
\hline Medical history & & & & & & & & & \\
\hline Charlson Comorbidity Index $>0$ & $36(33.6)$ & $54(42.2)$ & 0.225 & $23(42.6)$ & $101(37.5)$ & 0.540 & $59(36.6)$ & $155(39.0)$ & 0.632 \\
\hline Ischemic heart disease & $7(6.5)$ & $17(13.3)$ & 0.129 & $2(3.7)$ & $18(6.7)$ & 0.546 & $9(5.6)$ & $35(8.8)$ & 0.228 \\
\hline Diabetes & $23(21.5)$ & $28(21.9)$ & 1.000 & $15(27.8)$ & $58(21.6)$ & 0.372 & $38(23.6)$ & $86(21.7)$ & 0.653 \\
\hline Hypertension & $56(52.3)$ & $44(34.4)$ & 0.008 & $23(42.6)$ & $121(45.0)$ & 0.767 & $79(49.1)$ & $165(41.6)$ & 0.110 \\
\hline Hyperlipidemia & $38(35.5)$ & $20(15.6)$ & $<0.001$ & $17(31.5)$ & $69(25.7)$ & 0.400 & $55(34.2)$ & $89(22.4)$ & 0.005 \\
\hline Cerebrovascular disease & $3(2.8)$ & $8(6.2)$ & 0.234 & $3(5.6)$ & $17(6.3)$ & 1.000 & $6(3.7)$ & $25(6.3)$ & 0.308 \\
\hline Social history & & & & & & & & & \\
\hline Living arrangements & & & & & & & & & \\
\hline Living with family & $83(77.6)$ & $83(64.8)$ & Referent & $42(77.8)$ & $163(60.6)$ & Referent & $125(77.6)$ & $246(62.0)$ & Referent \\
\hline Living with others & $10(9.3)$ & $14(10.9)$ & 0.431 & $1(1.9)$ & $47(17.5)$ & 0.015 & $11(6.8)$ & $61(15.4)$ & 0.003 \\
\hline Living alone & $14(13.1)$ & $31(24.2)$ & 0.024 & $11(20.4)$ & $59(21.9)$ & 0.383 & $25(15.5)$ & $90(22.7)$ & 0.015 \\
\hline No. of people in household & & & & & & & & & \\
\hline$<3$ & $52(48.6)$ & $90(70.3)$ & 0.001 & $29(53.7)$ & $198(73.6)$ & 0.005 & $81(50.3)$ & $288(72.5)$ & $<0.001$ \\
\hline$\geq 3$ & $55(51.4)$ & $38(29.7)$ & & $25(46.3)$ & $71(26.4)$ & & $80(49.7)$ & $109(27.5)$ & \\
\hline Social support & & & & & & & & & \\
\hline Poorer social support (LSNS- $6 \leq 12$ ) & $65(60.7)$ & $98(76.6)$ & & $18(33.3)$ & $179(66.5)$ & & $83(51.6)$ & $277(69.8)$ & \\
\hline Better social support (LSNS-6 $>12$ ) & $42(39.3)$ & $30(23.4)$ & 0.011 & $36(66.7)$ & $90(33.5)$ & $<0.001$ & $78(48.4)$ & $120(30.2)$ & $<0.001$ \\
\hline Has family as caregiver & & & & & & & & & \\
\hline No & $24(22.4)$ & $47(36.7)$ & & $13(24.1)$ & $107(39.8)$ & & $37(23.0)$ & $154(38.8)$ & \\
\hline Yes & $83(77.6)$ & $81(63.3)$ & 0.022 & $41(75.9)$ & $162(60.2)$ & 0.031 & $124(77.0)$ & $243(61.2)$ & $<0.001$ \\
\hline MMSE score & $25.73 \pm 4.75$ & $25.05 \pm 4.16$ & 0.242 & $26.56 \pm 3.30$ & $25.71 \pm 4.23$ & 0.107 & $26.01 \pm 4.32$ & $25.50 \pm 4.22$ & 0.202 \\
\hline MMSE score $<24$ & $18(16.8)$ & $41(32.0)$ & 0.010 & $8(14.8)$ & $63(23.4)$ & 0.208 & $26(16.1)$ & $104(26.2)$ & 0.011 \\
\hline
\end{tabular}

Values are numbers with percentages in parentheses or means \pm SD. LSNS- $6=$ Lubbens Social Network Scale- $6 .{ }^{\text {a }}$ Computed using $\chi^{2}$ test. ${ }^{b}$ Computed using $t$ test. ${ }^{c}$ Depression defined as Geriatric Depression Scale-15 $\geq 5$ at baseline or history of doctor-diagnosed depression. 
Table 2. Multilevel regressions of cognitive function [ $\beta$ (standard deviation)] amongst elderly communities living in two integrated public housing precincts in Singapore

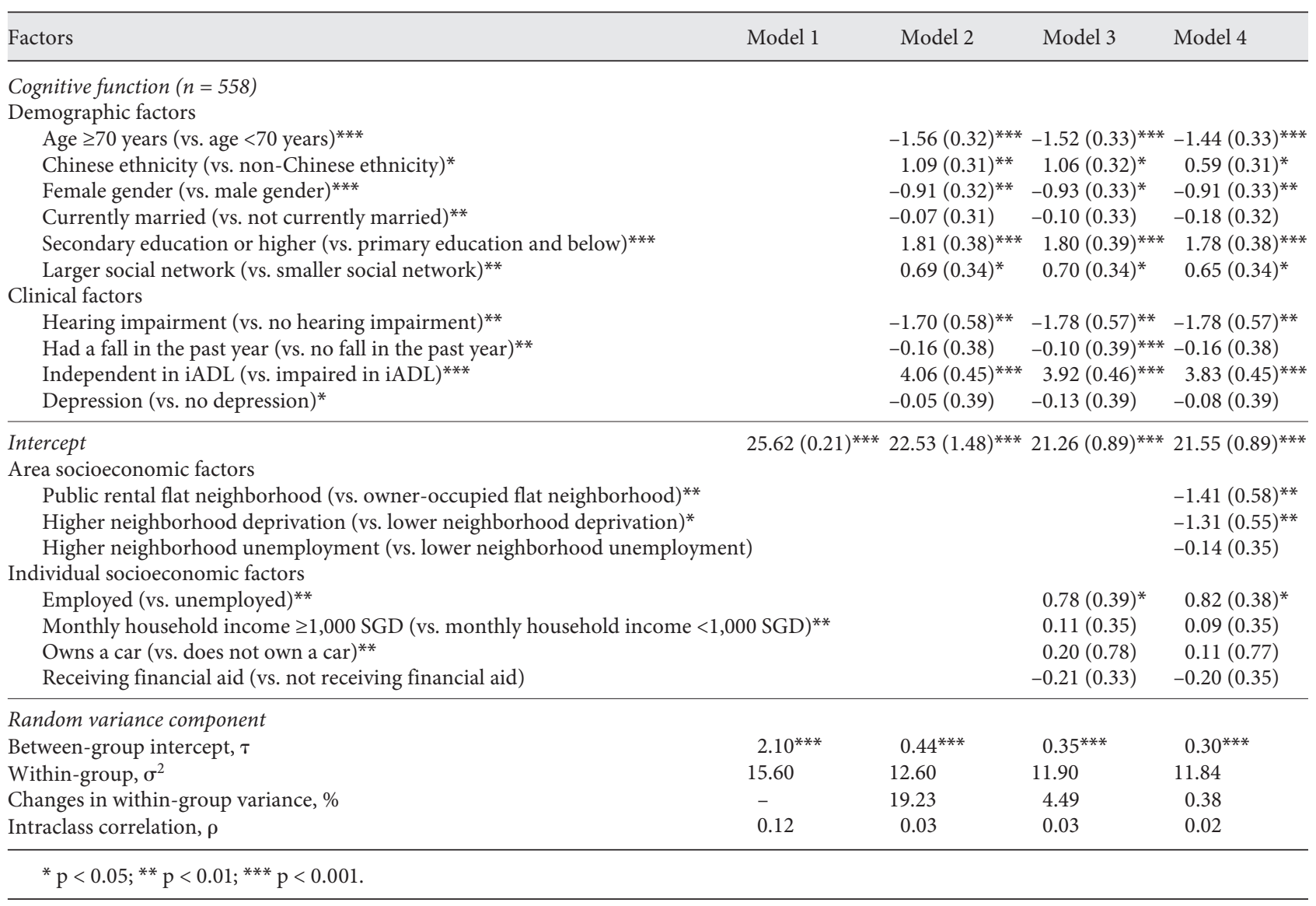

were on medical treatment. The prevalence of cognitive impairment was $26.2 \%(104 / 397)$ in rental blocks (low area SES), compared with 16.1\% (26/161) in owner-occupied blocks (higher area SES). The association between individual and neighborhood level socioeconomic characteristics with cognitive impairment in our study population is presented in tables 3 and 4. On univariate analysis (table 3), living in rental blocks (low area SES) was associated with cognitive impairment (odds ratio, OR 1.84, 95\% CI 1.15-2.97, $\mathrm{p}=0.011$ ). After adjustment for individual SES, other clinical factors, and demographic factors (including age, gender, educational level, and ethnicity), elderly living in the low area SES communities were more likely to have cognitive impairment (adjusted OR 5.13, 95\% CI 1.98-13.34, p = 0.001) compared to their counterparts in owner-occupied blocks (table 4). This association between area SES and cognitive impairment was also replicated, albeit to a lesser extent, when comparing the blocks with higher neighborhood disadvantage (as measured by the neighborhood disadvantage score) to those blocks with lower neighborhood disadvantage (adjusted OR 3.83, 95\% CI 1.65-8.85, $\mathrm{p}=0.002$ ). However, neighborhood unemployment (as measured by the neighborhood unemployment score) was not significantly associated with cognitive impairment. 
Table 3. Individual and area-level socioeconomic characteristics associated with prevalence of cognitive impairment $(\mathrm{n}=558)$ in community-dwelling elderly living in two integrated public housing precincts in Singapore

\begin{tabular}{|c|c|c|c|c|}
\hline \multirow[t]{2}{*}{ Factors } & \multicolumn{4}{|c|}{ Prevalence of cognitive impairment $(\mathrm{n}=558)$} \\
\hline & $\begin{array}{l}\text { No cognitive } \\
\text { impairment } \\
\mathrm{n}(\%)\end{array}$ & $\begin{array}{l}\text { Cognitive } \\
\text { impairment } \\
\mathrm{n}(\%)\end{array}$ & $\begin{array}{l}\text { Unadjusted OR } \\
(95 \% \mathrm{CI})\end{array}$ & $\mathrm{p}$ value \\
\hline \multicolumn{5}{|l|}{ Area level SES indicators } \\
\hline \multicolumn{5}{|l|}{ Type of block } \\
\hline Owner-occupied flats & $135(83.9)$ & $26(16.1)$ & 1.00 & \\
\hline Rental flats & $293(73.8)$ & $104(26.2)$ & $1.84(1.15-2.97)$ & 0.011 \\
\hline \multicolumn{5}{|l|}{ Neighborhood disadvantage score } \\
\hline Not disadvantaged & $173(79.7)$ & $44(20.3)$ & 1.00 & \\
\hline Disadvantaged & $255(74.8)$ & $86(25.2)$ & $1.33(0.88-2.00)$ & 0.184 \\
\hline \multicolumn{5}{|l|}{ Neighborhood unemployment score } \\
\hline Relatively lower unemployment & $149(78.0)$ & $42(22.0)$ & 1.00 & \\
\hline Relatively higher unemployment & $279(76.0)$ & $88(24.0)$ & $1.11(0.74-1.70)$ & 0.673 \\
\hline \multicolumn{5}{|l|}{ Individual level SES indicators } \\
\hline \multicolumn{5}{|l|}{ Employment status } \\
\hline Not working & $295(72.5)$ & $112(27.5)$ & 1.00 & \\
\hline Working & $133(88.1)$ & $18(11.9)$ & $0.36(0.21-0.61)$ & $<0.001$ \\
\hline \multicolumn{5}{|l|}{ Vehicle ownership } \\
\hline No & $405(75.8)$ & $129(24.2)$ & 1.00 & \\
\hline Yes & $23(95.8)$ & $1(4.2)$ & $0.14(0.02-1.02)$ & 0.024 \\
\hline \multicolumn{5}{|l|}{ Household income (monthly) } \\
\hline$<1,000$ SGD & $262(72.8)$ & $98(27.2)$ & 1.00 & \\
\hline$\geq 1,000$ SGD & $157(84.9)$ & $28(15.1)$ & $0.48(0.30-0.76)$ & 0.002 \\
\hline \multicolumn{5}{|l|}{ Financial aid } \\
\hline No & $356(77.4)$ & $104(22.6)$ & 1.00 & \\
\hline Yes & $72(73.5)$ & $26(26.5)$ & $1.23(0.75-2.04)$ & 0.430 \\
\hline
\end{tabular}

\section{Discussion}

Low area SES was significantly associated with poorer cognitive function and cognitive impairment in our study population of community-dwelling elderly in Singapore, a multiethnic Asian city state. Importantly, the main effect of area SES occurred independently of individual level SES, age, and education, highlighting that the area level effect was not merely the manifestation of compositional differences across neighborhoods. This contributes an Asian perspective to the growing body of research on neighborhood SES and mental health, and demonstrates that area level SES affects cognition in Asian societies as well. Several theories have been postulated as to how area level SES can affect cognition, largely drawn from experiences in Western societies. Such theories include: differences in distribution of cognitively stimulating resources in low-SES neighborhoods (such as health facilities and libraries); differences in cultural perceptions of illness and mental health in low-SES areas (e.g. perception of cognitive deficits as a normal part of ageing, delaying treatment and intervention); an ethnic enclave effect, and restricted opportunities for cognitive stimulation via social interaction in deprived neighborhoods $[5,10]$.

In our local context, the ethnic enclave effect is unlikely to play as large a role, because of government policy in ensuring a balanced ethnic mix in public housing that precludes the formation of ethnic enclaves. However, it is still possible that ethnicity can be a modifier of 
Table 4. Individual and area level socioeconomic characteristics independently associated with cognitive impairment $(\mathrm{n}=$ 558), after adjustment for other demographic and clinical variables, amongst elderly communities living in two integrated public housing precincts in Singapore

\begin{tabular}{|c|c|c|}
\hline Factors & $\begin{array}{l}\text { Adjusted }^{\mathrm{a}} \text { OR } \\
(95 \% \mathrm{CI})^{\mathrm{b}}\end{array}$ & $\mathrm{p}$ value \\
\hline \multicolumn{3}{|l|}{ Prevalence of cognitive impairment $(n=558)$} \\
\hline \multicolumn{3}{|l|}{ Demographic factors } \\
\hline Age $\geq 70$ years (vs. age $<70$ years) ${ }^{\mathrm{d}}$ & $2.42(1.36-4.30)$ & 0.003 \\
\hline Female gender (vs. male gender) ${ }^{\mathrm{d}}$ & $1.69(0.97-2.96)$ & 0.066 \\
\hline Currently married (vs. not currently married) ${ }^{\mathrm{c}}$ & $0.86(0.51-1.49)$ & 0.607 \\
\hline Secondary education or higher (vs. primary education and below) ${ }^{\mathrm{d}}$ & $0.26(0.10-0.66)$ & 0.005 \\
\hline Larger social network (vs. smaller social network) ${ }^{\mathrm{c}}$ & $0.60(0.33-1.09)$ & 0.091 \\
\hline \multicolumn{3}{|l|}{ Clinical factors } \\
\hline Visual impairment (vs. no visual impairment) ${ }^{\mathrm{c}}$ & $1.13(0.54-2.34)$ & 0.756 \\
\hline Hearing impairment (vs. no hearing impairment) ${ }^{\mathrm{c}}$ & $2.28(1.29-5.20)$ & 0.049 \\
\hline Had a fall in the past year (vs. no fall in the past year) ${ }^{c}$ & $1.17(0.64-2.15)$ & 0.613 \\
\hline Overweight (vs. not overweight) & $0.64(0.38-1.09)$ & 0.099 \\
\hline Independent in iADL (vs. impaired in iADL) ${ }^{\mathrm{d}}$ & $0.18(0.09-0.35)$ & $<0.001$ \\
\hline Charlson Comorbidity Index >0 (vs. Charlson Comorbidity Index =0) & $1.08(0.60-1.97)$ & 0.790 \\
\hline History of ischemic heart disease (vs. no history of ischemic heart disease) & $0.40(0.13-1.21)$ & 0.104 \\
\hline History of cerebrovascular disease (vs. no history of cerebrovascular disease) ${ }^{\mathrm{c}}$ & $2.17(0.77-6.06)$ & 0.141 \\
\hline Depression (vs. no depression) ${ }^{\mathrm{c}}$ & $1.10(0.61-2.02)$ & 0.742 \\
\hline Average systolic blood pressure, $\mathrm{mm} \mathrm{Hg}^{\mathrm{d}}$ & $1.02(1.01-1.03)$ & 0.013 \\
\hline \multicolumn{3}{|l|}{ Area socioeconomic factors } \\
\hline Public rental flat neighborhood (vs. owner-occupied flat neighborhood) ${ }^{\mathrm{c}}$ & $5.13(1.98-13.34)$ & 0.001 \\
\hline Higher neighborhood deprivation (vs. lower neighborhood deprivation) & $3.83(1.65-8.85)$ & 0.002 \\
\hline Higher neighborhood unemployment (vs. lower neighborhood unemployment) & $1.45(0.81-2.59)$ & 0.208 \\
\hline \multicolumn{3}{|l|}{ Individual socioeconomic factors } \\
\hline Employed (vs. unemployed)d & $0.76(0.37-1.58)$ & 0.464 \\
\hline Monthly household income $\geq 1,000$ SGD (vs. monthly household income $<1,000$ SGD) ${ }^{c}$ & $0.67(0.34-1.25)$ & 0.208 \\
\hline Owns a car (vs. does not own a car) ${ }^{c}$ & $0.33(0.04-2.73)$ & 0.302 \\
\hline Receiving financial aid (vs. not receiving financial aid) & $1.10(0.57-2.11)$ & 0.780 \\
\hline
\end{tabular}

${ }^{a}$ Criterion for entry of demographic and clinical factors into the final model on multivariate analysis was $\mathrm{p}<0.2$ on univariate analysis. Demographic factors entered into the model included age, gender, marital status, education level, and social network. Clinical factors entered into the model included: visual impairment; hearing impairment; had a fall in the past 1 year; overweight; impairment in iADL; having medical comorbidities as quantified using the Charlson Comorbidity Index; history of ischemic heart disease; history of cerebrovascular disease; history of depression, and average systolic blood pressure. All area and individual level indicators of socioeconomic status were also entered into the model. We did not enter impairment in basic ADL (measured via Barthel Index) into the final model because of significant collinearity between measurements of basic ADL and measurements of iADL $(|r|>0.6)$. Collinear variables were omitted from the final models in order of decreasing $\mathrm{p}$ values.

${ }^{\mathrm{b}}$ ORs reported are adjusted for all variables presented in model.

${ }^{c} \mathrm{p}$ value of $<0.05$ on univariate analysis.

${ }^{\mathrm{d}}$ p value of $<0.001$ on univariate analysis.

the effects of SES on cognitive function. Singapore's high urban density means that low- and high-SES communities often share the same amenities, and disparities in distribution of cognitively stimulating resources are therefore less marked. However, the opportunities for social interaction in high-rise, high-density public housing, a common feature in Singapore's urban landscape, are worth closer examination. Singapore, with a small land area of just 690 $\mathrm{km}^{2}$, has often been described as an urban laboratory for high-rise public housing, given that the vast majority of the resident population stays in such housing estates [51]. Research sug- 
gests that in high-rise developments, the overall sense of residential community is low; most residents interact only with neighbors on their own floor and are strangers to the vast majority of people sharing the same dwelling $[52,53]$. In Singapore, while satisfaction with the quality of amenities and standard of high-rise public housing is high $[32,54]$ and there is less concern about safety and security in such estates [55], there is concern about the effect of such housing on social interaction. In the words of one author, 'In tall residential buildings, there is no need to borrow garden tools and when the 24-hour provision shop is just an elevator ride away, there is little reason to borrow a cup of sugar from a neighbor' [56]. Thus, Singapore's urban landscape, with reduced opportunities for social interaction, could further reinforce the possible link between low area SES, limited social participation, and cognitive functioning. Residents of poor neighborhoods, regardless of their own class, are likely to have interaction with neighbors who, because of disadvantage, may be unable to offer extensive cognitive stimulation, constrained by limited education and financial stress, whereas residents in more affluent neighborhoods are exposed to neighbors who can provide more extensive cognitive stimulation [10]. Locally, although there is no data directly linking social interaction to cognitive impairment, other local studies have linked social networks to depressive symptoms among the elderly [38], and in turn, depressive symptoms to cognitive impairment [57]. Additionally, in densely urbanized Singapore, close juxtaposition of richer communities in proximity to poorer neighborhoods could exacerbate the health consequences of poverty, as suggested by the 'local social inequality' model $[14,58]$. Higher income inequality is also associated with lower societal trust in several studies [59], including Asian societies [60], and diminished trust can lead to social withdrawal, further social isolation and negative effects on cognition. Urban planning of living space can be better designed to foster social interaction and, hopefully, improve cognitive function of the elderly staying in such estates. Given Singapore's unique constraints on living space, though, high-rise public housing is likely to persist as a significant component of the built environment. Similarly, in other rapidly urbanizing Asian cities with space constraints, high-rise housing is likely to increase [56]. Hence, apart from rethinking urban planning, interventions are also important in targeting at-risk groups within these low-SES communities, in order to slow cognitive decline and ease access to mental health services. Many cultural misperceptions and poor awareness about cognitive impairment and dementia exist even in developed countries [61, 62 . More needs to be done to encourage participation in preventive and early detection programs.

The limitations of our study are as follows. Our study design was cross-sectional in nature; hence we can only draw associations between neighborhood SES and cognitive impairment, and cannot infer causality. In addition, we did not account for the length of residence, as such data was not available. Furthermore, this study was only carried out in two geographical sites and a limited number of blocks $(n=15)$ as our aim was to compare a small number of purposely selected contrasting neighborhoods. While such methods have their strengths $[4,63,64]$, their weakness is in the generalizability of results [4]. Our results might not be fully generalizable to other integrated housing precincts in Singapore, and the owner-occupied blocks in our study may not be fully representative of national demographic patterns as a whole. We note, however, that the demographic makeup of our owner-occupied blocks (higher area SES) is similar to national averages for similar types of blocks (e.g. 64.6\% Chinese ethnicity vs. $68.4 \%$ Chinese ethnicity nationally; employment rates of 26.1 vs. $29 \%$ nationally; $51.3 \%$ with monthly household income $\geq 1,000$ SGD, compared with median household income of 1,267 SGD nationally; $50.3 \%$ with household size $<3$, compared with median household size of 2 nationally). Also, these findings may be relevant in the local sociocultural milieu, but might not be easily generalizable to other Asian societies and other populations. In addition, we used the MMSE to diagnose cognitive impairment. While its use and 
Wee et al.: Individual and Area Level Socioeconomic Status and Its Association with

Cognitive Function and Cognitive Impairment among Community-Dwelling Elderly

the cutoffs were locally validated $[25,28]$, the MMSE is only a screening tool for cognitive impairment and cannot diagnose dementia.

In conclusion, living in a low-SES community was independently associated with poorer cognitive function and cognitive impairment among community-dwelling elderly living in integrated public housing precincts in Singapore, an urbanized Asian city state. This association was independent of individual SES as well as demographic and clinical factors. Causal pathways by which neighborhood deprivation can potentially affect cognitive function among elderly in urbanized Asian societies need to be better understood.

\section{Acknowledgements}

We thank the Neighborhood Health Screening Organising Committee 2012; Saw Swee Hock School of Public Health; Health Promotion Board; Southwest Community Development Council, Taman Jurong Community Centre, Macpherson Community Centre, Singhealth Polyclinic (Geylang), National Healthcare Group Polyclinic (Jurong), for providing the non-financial resources to organize this program and supporting this study. The Saw Swee Hock School of Public Health provided funding support for the purchasing of medical consumables.

\section{Disclosure Statement}

The authors declare no conflicts of interest.

\section{References}

-1 Schmand B, Smit J, Lindeboom J, Smits C, Hooijer C, Jonker C, Deelman B: Low education is a genuine risk factor for accelerated memory decline and dementia. J Clin Epidemiol 1997;50:1025-1033.

-2 Lee S, Kawachi I, Berkman LF, Grodstein F: Education, other socioeconomic indicators, and cognitive function. Am J Epidemiol 2003;157:712-720.

-3 Marengoni A, Fratiglioni L, Bandinelli S, Ferrucci L: Socioeconomic status during lifetime and cognitive impairment no-dementia in late life: the population-based aging in the Chianti Area (InCHIANTI) Study. J Alzheimers Dis 2011;24:559-568.

-4 Diez Roux AV: Investigating neighborhood and area effects on health. Am J Public Health 2001;91: 1783-1789.

-5 Wight RG, Aneshensel CS, Miller-Martinez D, Botticello AL, Cummings JR, Karlamangla AS, Seeman TE: Urban neighborhood context, educational attainment, and cognitive function among older adults. Am J Epidemiol 2006;163:1071-1078.

-6 Espino DV, Lichtenstein MJ, Palmer RF, Hazuda HP: Ethnic differences in mini-mental state examination (MMSE) scores: where you live makes a difference. J Am Geriatr Soc 2001;49:538-548.

-7 Basta NE, Matthews FE, Chatfield MD, Brayne C: Community-level socio-economic status and cognitive and functional impairment in the older population. Eur J Public Health 2008;18:48-54.

-8 Lang IA, Llewellyn DJ, Langa KM, Wallace RB, Huppert FA, Melzer D: Neighborhood deprivation, individual socioeconomic status, and cognitive function in older people: analyses from the English Longitudinal Study of Ageing. J Am Geriatr Soc 2008;56:191-198.

-9 Sheffield KM, Peek MK: Neighborhood context and cognitive decline in older Mexican Americans: results from the Hispanic Established Populations for Epidemiologic Studies of the Elderly. Am J Epidemiol 2009;169:1092-1101.

10 Aneshensel CS, Ko MJ, Chodosh J, Wight RG: The urban neighborhood and cognitive functioning in late middle age. J Health Soc Behav 2011;52:163-179. 
Cognitive Function and Cognitive Impairment among Community-Dwelling Elderly

-11 Zeki Al Hazzouri A, Haan MN, Osypuk T, Abdou C, Hinton L, Aiello AE: Neighborhood socioeconomic context and cognitive decline among older Mexican Americans: results from the Sacramento Area Latino Study on Aging. Am J Epidemiol 2011;174:423-431.

-12 Shih RA, Ghosh-Dastidar B, Margolis KL, Slaughter ME, Jewell A, Bird CE, Eibner C, Denburg NL, Ockene J, Messina CR, Espeland MA: Neighborhood socioeconomic status and cognitive function in women. Am J Public Health 2011;101:1721-1728.

13 Glass TA, Balfour JL: Neighborhoods, aging and functional limitations; in Kawachi I, Berkman LF (eds): Neighborhoods and Health. New York, Oxford University Press, 2003, pp 303-334.

-14 Stafford M, Marmot M: Neighbourhood deprivation and health: does it affect us all equally? Int J Epidemiol 2003;32:357-366.

-15 Riva M, Bambra C, Curtis S, Gauvin L: Collective resources or local social inequalities? Examining the social determinants of mental health in rural areas. Eur J Public Health 2011;21:197-203.

16 Barnes LL, Cagney KA, Mendes DLCF: Social resources and cognitive function in older persons; in Hofer SM, Alwin DF (eds): Handbook of Cognitive Aging: Interdisciplinary Perspectives. Sage, Los Angeles, CA, 2008, pp 603-613.

-17 Conroy RM, Golden J, Jeffares I, O’Neill D, McGee H: Boredom-proneness, loneliness, social engagement and depression and their association with cognitive function in older people: a population study. Psychol Health Med 2010;15:463-473.

-18 Yen YC, Yang MJ, Shih CH, Lung FW: Cognitive impairment and associated risk factors among aged community members. Int J Geriatr Psychiatry 2004;19:564-569.

$>19$ Woo J, Ho SC, Lau S, Lau J, Yuen YK: Prevalence of cognitive impairment and associated factors among elderly Hong Kong Chinese aged 70 years and over. Neuroepidemiology 1994;13:50-58.

-20 Hamid TA, Krishnaswamy S, Abdullah SS, Momtaz YA: Sociodemographic risk factors and correlates of dementia in older Malaysians. Dement Geriatr Cogn Disord 2010;30:533-539.

-21 Lee Y, Back JH, Kim J, Byeon H: Multiple socioeconomic risks and cognitive impairment in older adults. Dement Geriatr Cogn Disord 2010;29:523-529.

-22 Yao YH, Xu RF, Tang HD, Jiang GX, Wang Y, Wang G, Chen SD, Cheng Q: Cognitive impairment and associated factors among the elderly in the Shanghai suburb: findings from a low-education population. Neuroepidemiology 2010;34:245-252.

23 Ali I: Inequality and the imperative for inclusive growth in Asia. Asian Development Review 2007; 24.

24 Lim HJ, Lim JP, Anthony P, Yeo DH, Sahadevan S: Prevalence of cognitive impairment amongst Singapore's elderly Chinese: a community-based study using the ECAQ and the IQCODE. Int J Geriatr Psychiatry 2003;18:142-148.

-25 Ng TP, Niti M, Chiam PC, Kua EH: Ethnic and educational differences in cognitive test performance on Mini-Mental State Examination in Asians. Am J Geriatr Psychiatry 2007;15:130-139.

26 Economic and Social Commission for Asia and the Pacific (ESCAP), Bangkok with Japanese Organisation for International Cooperation in Family Planning, Inc. Tokyo: Population Ageing in Asia and the Pacific. New York, United Nations, 1996.

27 Phua HP, Chua AV, Ma S, Heng D, Chew SK: Singapore's burden of disease and injury 2004. Singapore Med J 2009;50:468-478.

28 Sahadevan S, Lim PP, Tan NJ, Chan SP: Diagnostic performance of two mental status tests in the older Chinese: influence of education and age on cut-off values. Int J Geriatr Psychiatry 2000;15: 234-241.

29 Department of Statistics, Government of Singapore: Key household characteristics and household income trends 2011. http://www.singstat.gov.sg/pubn/papers/people/pp-s18.pdf (accessed February 17, 2012).

30 Singstat.gov.sg: Singapore: Department of Statistics, Government of Singapore; c2009-10. http:// www.singstat.gov.sg/stats/keyind.html (accessed February 15, 2010).

31 Hdb.gov.sg: Singapore: Housing and Development Board, Government of Singapore; c2009-10. http://www.hdb.gov.sg/fi10/fi10323p.nsf/w/RentDirectHDBRentDeposit?OpenDocument (accessed April 15, 2010).

32 Housing and Development Board, Government of Singapore: Public Housing in Singapore: Residents' Profile, Housing Satisfaction and Preferences: HDB Sample Household Survey 2008. Singapore, Housing Development Board, 2009. 
Cognitive Function and Cognitive Impairment among Community-Dwelling Elderly

33 Department of Statistics, Government of Singapore: Key Household Income Trends, 2008. Singapore, Department of Statistics, 2009.

34 Housing and Development Board, Government of Singapore: Rents and Deposits. http://www.hdb. gov.sg/fi10/fi10323p.nsf/w/RentDirectHDBRentDeposit?OpenDocument (accessed February 17, 2012).

-35 Ng TP, Niti M, Chiam PC, Kua EH: Physical and cognitive domains of the Instrumental Activities of Daily Living: validation in a multiethnic population of Asian older adults. J Gerontol A Biol Sci Med Sci 2006;61:726-735.

-36 Shah S, Vanclay F, Cooper B: Improving the sensitivity of the Barthel Index for stroke rehabilitation. J Clin Epidemiol 1989;42:703-709.

- 37 Charlson ME, Pompei P, Ales KL, MacKenzie CR: A new method of classifying prognostic comorbidity in longitudinal studies: development and validation. J Chronic Dis 1987;40:373-383.

- 38 Chan A, Malhotra C, Malhotra R, Ostbye T: Living arrangements, social networks and depressive symptoms among older men and women in Singapore. Int J Geriatr Psychiatry 2011;26:630-639.

-39 Lubben J, Blozik E, Gillmann G, Iliffe S, von Renteln Kruse W, Beck JC, Stuck AE: Performance of an abbreviated version of the Lubben Social Network Scale among three European communitydwelling older adult populations. Gerontologist 2006;46:503-513.

-40 Nyunt MS, Fones C, Niti M, Ng TP: Criterion-based validity and reliability of the Geriatric Depression Screening Scale (GDS-15) in a large validation sample of community-living Asian older adults. Aging Ment Health 2009;13:376-382.

41 Health Promotion Board, Government of Singapore: Nurture Your Mind. http://www.hpb.gov.sg/ programmes/article.aspx?id=350 (accessed February 28, 2012).

-42 Berkman LF: The association between educational attainment and mental status examinations: of etiologic significance for senile dementias or not? J Chronic Dis 1986;39:171-175.

-43 Crum RM, Anthony JC, Bassett SS, Folstein MF: Population-based norms for the Mini-Mental State Examination by age and educational level. JAMA 1993;269:2386-2391.

-44 Wee LE, Koh GC: Individual and neighborhood social factors of hypertension management in a lowsocioeconomic status population: a community-based case-control study in Singapore. Hypertens Res 2012;35:295-303.

-45 Wee LE, Koh GC: The effect of neighborhood, socioeconomic status and a community-based program on multi-disease health screening in an Asian population: a controlled intervention study. Prev Med 2011;53:64-69.

-46 Aneshensel CS, Wight RG, Miller-Martinez D, Botticello AL, Karlamangla AS, Seeman TE: Urban neighborhoods and depressive symptoms among older adults. J Gerontol B Psychol Sci Soc Sci 2007; 62:S52-S59.

47 Kim D: Blues from the neighborhood? Neighborhood characteristics and depression. Epidemiol Rev 2008;30:101-117.

48 Wee LE, Koh GC, Yeo WX, Chin RT, Wong J, Seow B: Screening for cardiovascular disease risk factors in an urban low-income setting at baseline and post intervention: a prospective intervention study. Eur J Prev Cardiol 2012, E-pub ahead of print.

-49 Silver E, Mulvey EP, Swanson JW: Neighborhood structural characteristics and mental disorder: Faris and Dunham revisited. Soc Sci Med 2002;55:1457-1470.

-50 Ng TP, Niti M, Chiam PC, Kua EH: Prevalence and correlates of functional disability in multiethnic elderly Singaporeans. J Am Geriatr Soc 2006;54:21-29.

51 Koolhaas R, Mau B: Small, Medium, Large, Extra-Large. New York, The Monacelli Press, 2005.

-52 Forrest R, La Grange A, Ngai-Ming Y: Neighbourhood in a high rise, high density city: some observations on contemporary Hong Kong. Sociol Rev 2002;50:215-240.

53 Gifford R: The consequences of living in high-rise buildings. Architectural Science Review 2006;50: $1-16$.

-54 Yuen B, Yeh A, Appold SJ, Earl G, Ting J, Kwee LK: High-rise living in Singapore public housing. Urban Studies 2006;43:583-600.

-55 Yuen B: Romancing the high-rise in Singapore. Cities 2005;22:3-13.

56 Yuen B, Yeh A: High-Rise Living in Asian Cities. New York, Springer, 2011.

-57 Chuan SK, Kumar R, Matthew N, Heok KE, Pin NT: Subsyndromal depression in old age: clinical significance and impact in a multi-ethnic community sample of elderly Singaporeans. Int Psychogeriatr 2008;20:188-200. 
Wee et al.: Individual and Area Level Socioeconomic Status and Its Association with

Cognitive Function and Cognitive Impairment among Community-Dwelling Elderly

- 58 Galea S, Freudenberg N, Vlahov D: Cities and population health. Soc Sci Med 2005;60:1017-1033.

- 59 Kondo N, Sembajwe G, Kawachi I, van Dam RM, Subramanian SV, Yamagata Z: Income inequality, mortality, and self rated health: meta-analysis of multilevel studies. BMJ 2009;339:b4471.

-60 Ichida Y, Kondo K, Hirai H, Hanibuchi T, Yoshikawa G, Murata C: Social capital, income inequality and self-rated health in Chita peninsula, Japan: a multilevel analysis of older people in 25 communities. Soc Sci Med 2009;69:489-499.

-61 Yeo LH, Horan MA, Jones M, Pendleton N: Perceptions of risk and prevention of dementia in the healthy elderly. Dement Geriatr Cogn Disord 2007;23:368-371.

62 Ikels C: The experience of dementia in China. Cult Med Psychiatry 1998;22:257-283.

-63 Ellaway A, Macintyre S: Does where you live predict health related behaviours? A case study in Glasgow. Health Bull (Edinb) 1996;54:443-446.

-64 Macintyre S, Ellaway A: Neighbourhood cohesion and health in socially contrasting neighbourhoods: implications for the social exclusion and public health agendas. Health Bull (Edinb) 2000;58: $450-456$. 